\title{
Benchmarking Patient Delays in Ontario's Emergency Departments: What Are We Waiting For?
}

The he problem of prolonged patient wait times in Ontario emergency departments (ED) has, once again, become front-page news. Renewed interest stems largely from two factors. The first concerns reports of lengthy delays occurring before the unloading of ambulance patients in crowded EDs (Gray 2005); the second is a high-profile coroner's case of a young woman who died after leaving an ED when she was informed she would have to wait eight hours to see a physician (Blatchford 2005; Ontario Emergency 2005).

The most common reason for prolonged waits is fully occupied ED stretchers; thus there is a lack of places for medical staff to receive new patients. In general, the most acutely ill patients experience longer total wait times (registration to discharge), a result of more intensive levels of assessment, investigation and treatment than that required by less urgent patients. Paradoxically, these patients may also wait longer for initial physician assessment than patients with minor illnesses or injuries. The reason is that the ED areas serving them are more likely to be filled with other patients undergoing assessments and treatments, or waiting for an inpatient bed. As shown in Table 1, 90\% of ED patients in the "urgent" category receive physician assessments within 2.9 hours -47 minutes longer than patients with non-urgent problems, and the longest wait duration of the five triage acuity categories.

Total wait times in EDs vary substantially throughout Local Health Integration Networks (LHINs) in Ontario (see Figure 1). Compared to a provincial average of 6.6 hours (within which $90 \%$ of patients are seen), there is a 2.6 -fold difference between the fastest-performing LHIN, at 4.2 hours (South West), to the slowestperforming LHIN, at 11.2 hours (Toronto Central). Such wide variation needs to be considered in the context of local differences among LHINs such as patient case-mix, availability of inpatient beds and existing alternatives to EDs for care of patients with minor complaints.

Various solutions to the ED wait problem have been proposed, including increasing inpatient bed capacity, increasing ED physical space, speeding up test turnaround times and reducing patient inflow by diverting patients with minor illnesses or injuries elsewhere for care. In the right context, all of these initiatives might work to reduce waittimes for some patients. However, solutions must be tailored to resolve predominant local causes of wait times, as it is unlikely that a "one size fits all" remedy is the answer.

So where do we go from here? One way forward is to examine the approaches of other jurisdictions that have successfully reduced ED wait times. The best-documented example is the National Health Service (NHS) in the UK, where dramatic reductions in ED wait times were achieved following the adoption, in 2001, of a country-wide target of four hours or less total wait-time for $98 \%$ of ED patients (Alberti 2005). In 2005, the NHS reported that less than $4 \%$ of ED patients spend more than four hours in an ED (Alberti 2005 ), compared to about $23 \%$ in Ontario and about $28 \%$ in the US (McCaig and Burt 2004).

\begin{tabular}{l}
$\begin{array}{l}\text { Table 1. Time to First Physician Assessment and Total Wait Time } \\
\text { after Patient Registration in an ED, by Triage Acuity Level, in Ontario, } \\
\text { 2003-2004 }\end{array}$ \\
\begin{tabular}{lcc} 
Triage acuity level* & $\begin{array}{c}\text { Time to first } \\
\text { physician } \\
\text { (90th percentile, hours) }\end{array}$ & $\begin{array}{c}\text { Total wait-time } \dagger \\
\text { assessment } \\
\text { (90th percentile, hours) }\end{array}$ \\
\hline Resuscitation & 0.6 & 8.7 \\
Emergent & 2.0 & 10.3 \\
Urgent & 2.9 & 8.4 \\
Less urgent & 2.6 & 4.7 \\
Non-urgent & 2.1 & 3.2
\end{tabular} \\
\hline
\end{tabular}

${ }^{*}$ Canadian Triage and Acuity Scale assigned when patient registers.

$\dagger$ Time from patient registration to discharge from ED.

Data source: Canadian Institute for Health Information - National Ambulatory Care Reporting System.

Figure 1. Total Wait Time (Registration to Discharge) Within Which $90 \%$ of Patients are Treated in Ontario EDs, by Local Health Integration Network, 2003-2004

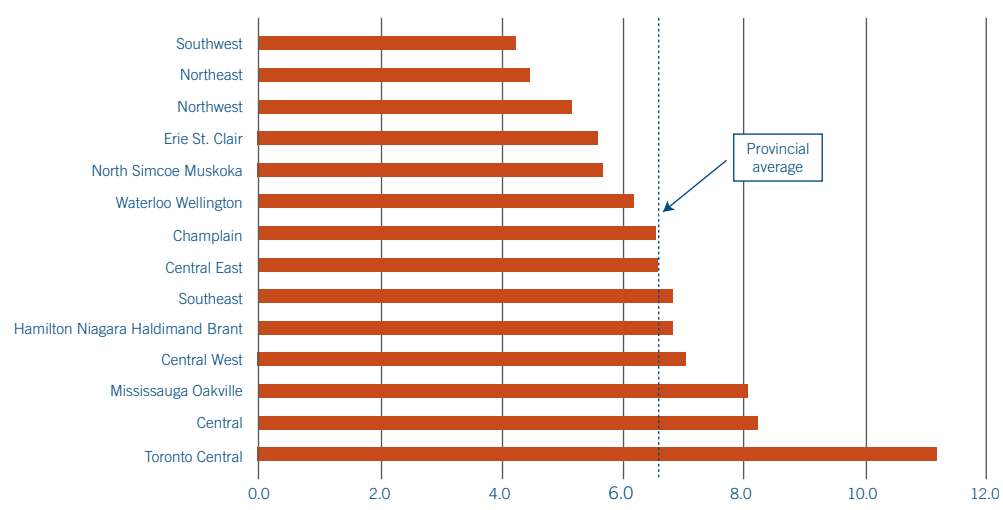

Data source: Canadian Institute for Health Information - National Ambulatory Care Reporting System. 
Target-setting alone is unlikely to produce meaningful results. The UK strategy included several key components, such as financial incentives, accountability measures and additional investments such as enhanced access to afterhours alternatives to EDs (Alberti 2005). However, despite the substantially improved performance reported by the NHS, $20 \%$ of EDs in the UK have not attained the target, and some have complained of inadequate involvement of senior hospital administration in the effort (British Medical Association [BMA] 2005). In addition, a singular focus on achieving the wait-time target has been blamed for reduced attention to quality of patient care, inappropriate admissions, overly hasty discharges and "creative accounting" or manipulation of data to attain the target (BMA 2005; House of Commons Public Accounts Committee 2005).

However, the process of moving toward a benchmark may be as important as achieving it, and likely deserves equal emphasis. The NHS has adopted a more balanced strategy for another key quality-of-care indicator. The NHS measures the "call-to-needle" time for eligible patients with acute myocardial infarction (period from 911 call to delivery of clot-busting thrombolytic drugs) in terms of the absolute proportion of patients treated within the recommended benchmark time and the annual incremental improvement in that proportion (Department of Health 2003). Both measures can be used to gauge performance; two hospitals with differing absolute performance but similar incremental improvements could each be considered good performers. Implementation of performance targets may be more successful if there is allowance for some degree of variation in recognition of regional differences, and by ensuring that measures designed to help hospitals achieve the targets are appropriate to the local context.

Implementation of benchmarks has led to improved care in other contexts (Jha et al. 2003; Rogers et al. 2000), and Canada is now beginning to define target wait times for several medical procedures (Wait Time Alliance 2005). The UK experience suggests that wait-time benchmarks can be successful in EDs. If such efforts to reduce wait times are adopted in Ontario, it is critical to ensure that quality of care is not compromised and potentially improves. Good performance should include regular incremental improvement as opposed to the sole attainment of an absolute target. Local input into benchmark-setting and investment of new ED system resources are important, and close involvement of senior hospital administrators is required. Taken together, these may lead to substantially improved patient care in Ontario's EDs.

\section{References}

Alberti, K.G. 2005. Transforming Emergency Care in England (pp. 1-44). London: National Health Service.

Blatchford, C. 2005, March 31. “ER Delays Are Common and Deadly, Doctor Says." The Globe and Mail, p. A1.
British Medical Association. 2005. BMA Survey of A\&E Waiting Times (pp. 1-16). London: Author.

Department of Health, UK Government. 2003. Review of Early Thrombolysis: Faster and Better Treatment for Heart Attack Patients (pp. 1-17). London: Author.

Gray, J. 2005, January 12. “Hospital Delays Cost \$5-Million, Paramedics Say." The Globe and Mail, p. A11.

House of Commons Public Accounts Committee. 2005. Department of Health: Improving Emergency Care in England (pp. 1-22). London: The Stationary Office Limited.

Jha, A.K., J.B. Perlin, K.W. Kizer and R.A. Dudley. 2003. "Effect of the Transformation of the Veterans Affairs Health Care System on the Quality of Care." New England Journal of Medicine 348: 2218-27.

McCaig, L.F. and C.W. Burt. 2004. "National Hospital Ambulatory Medical Care Survey: 2002 Emergency Department Summary.” Advance Data: 1-34.

“Ontario Emergency Room Waits Fatal, Health Officials Say." 2005 , April 1. CBC News Online. Retrieved April 12, 2005. $<$ toronto.cbc.ca/regional/servlet/View?filename=toemergency20050401>.

Rogers, W.J., J.G. Canto, C.T. Lambrew, A.J. Tiefenbrunn, B. Kinkaid, D.A. Shoultz et al. 2000. "Temporal Trends in the Treatment of Over 1.5 Million Patients with Myocardial Infarction in the US from 1990 Through 1999: The National Registry of Myocardial Infarction 1, 2 and 3." Journal of the American College of Cardiology 36: 2056-63.

Wait Time Alliance. 2005. No More Time to Wait: Toward Benchmarks and Best Practices in Wait Time Management (pp. 1-65). Ottawa, Canadian Medical Association.

\section{About the Author}

Michael Schull, BA, MSc, MD, FRCPC, has been a scientist at ICES since March 2000. He is an Assistant Professor in the Departments of Medicine (Division of Emergency Medicine) and Health Policy, Management and Evaluation at the University of Toronto. He also holds a faculty appointment in the Clinical Epidemiology Unit of Sunnybrook and Women's College Health Sciences Centre. Dr. Schull sits on the Research Advisory Committee of the Ontario Ministry of Health's Emergency Health Services Branch. He is a practising staff emergency physician at Sunnybrook \& Women's and supervises the clinical and research training of residents in the Royal College Emergency Medicine program.

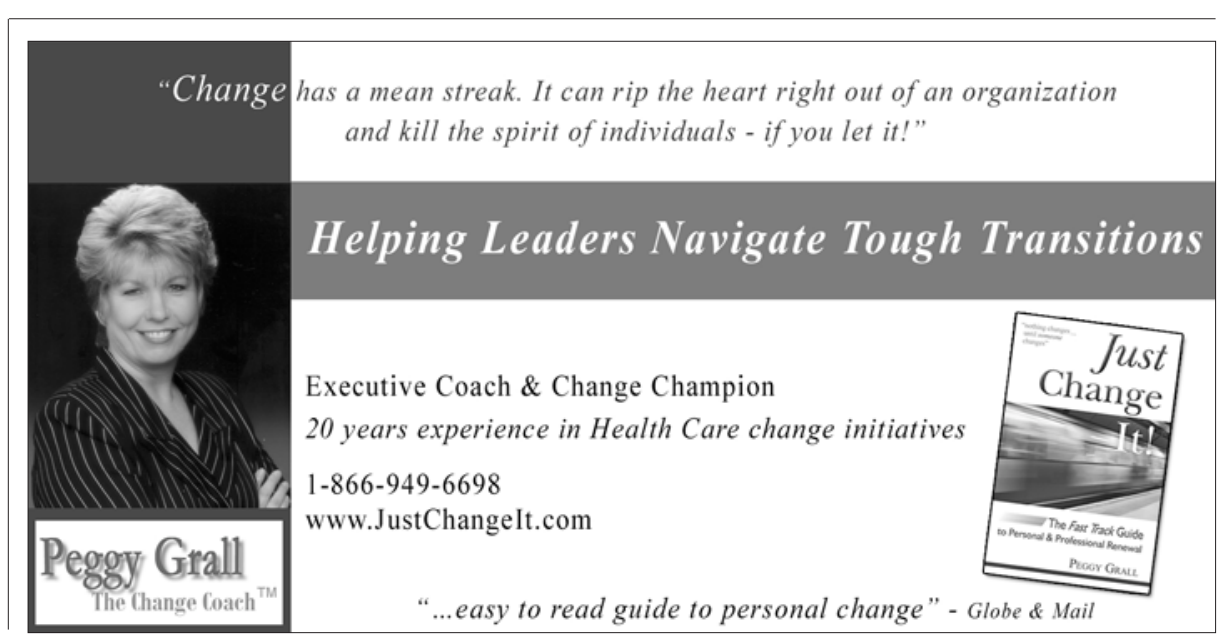

